\title{
Model Peningkatan Kinerja Dosen Universitas Boyolali di Jawa Tengah Sebuah pendekatan Fourfold C Character
}

\author{
Dasmadi \\ Universitas Boyolali \\ dasmadi@uby.ac.id
}

\begin{abstract}
Abstrak
Penelitian ini membahas peningkatan kinerja melalui perilaku sportsmanship yang didukung dengan pendekatan Communication, Collaboration, Critical Thinking and Problem Solving, Creativity and Innovation. Penelitian ini bertujuan untuk menyusun model pengembangan model pengembangan sportmanship behaviour dalam meningkatkan kinerja dengan didukung pendekatan 4C pada dosen Universitas Boyolali. Populasi penelitian ini adalah seluruh dosen di universitas Boyolali, Jawa Tengah. Sampel ditentukan dengan proportionate random sampling sejumlah 115 dosen. Data didapatkan melalui kuesioner skala likert $1-5$ dan dianalisis dengan menggunakan software SPSS. Artikel ini menawarkan pemahaman yang lebih dalam tentang masalah kontekstual penting yang berdampak pada upaya implementasi strategi pendekatan Fourfold C Approach dalam meningkatkan kinerja Dosen yaitu Communication, Collaboration, Critical Thinking and Problem Solving, Creativity and Innovation. Hasil penelitian ini menunjukkan bahwa kinerja DOsen dapat ditingkatkan melalui melalui Critical Thinking and Problem Solving; collaboration dan Creativity. Communication skill tidak mampu menjadi predictor kinerja Dosen.
\end{abstract}

Kata Kunci Communication; Collaboration; Critical Thinking and Problem Solving; Creativity and Innovation; performance

\section{PENDAHULUAN}

Dalam menghadapi Revolusi Industri 4.0 yang merupakan era inovasi disruptif sehingga mampu menciptakan berbagai macam pasar baru. Inovasi yang sangat pesat ini bisa memiliki dampak positif maupun negatif pada pasar eksisting dan lebih parah lagi, mampu menciptakan tehnologi yang sudah ada. Menghadapi tantangan tersebut, dunia pendidikan sebagai penghasil sumberdaya manusia yang berkualitas dituntut untuk berubah juga.

Era disrupsi merupakan era terjadinya perubahan dari cara manual menjadi serba digital. Dalam era disrupsi terjadi perubahan drastis, mengubah tatanan kehidupan manusia dalam berbagai bidang termasuk dalam bidang jasa dan menjadi dilema bagi produsen yang bergelut pada bidang jasa Pendidikan. Dimana disatu sisi, lingkungan pendidikan diharapkan mampu mendidik mahasiswanya menjadi insan yang berkarakter, beretika, dan berperilaku sesuai dengan nilai nilai yang berlaku di masyarakat. Namun disisi lain universitas harus menyesuaikan dengan perubahan era disruptif dituntut untuk mengikuti perubahan menuju era digitalisasi. 
Pada era ini Dosen harus mengembangkan diri untuk mampu menerapkan teknologi digital, namun juga harus mampu menguatkan karakter mahasiswanya. Menghadapi era digitalisasi juga memaksa Dosen untuk mengembangkan diri menuju pola kolaborasi digital dimana bentuk kolaborasi dan koordinasi lintas sektoral dilakukan selain dengan tatap muka juga dengan menggunakan perangkat tehnologi. Dalam era digital, kolaborasi menjadi satu tantangan tersendiri dimana pola komunikasi dan sosialisasi telah berubah.

Kawasan Asia Tenggara saat ini telah memasuki babak Economic ASEAN Community atau Masyarakat Ekonomi ASEAN (MEA). Secara garis besar tujuan didirikannya MEA adalah untuk menghadapi persaingan global, adanya aliran bebas barang, jasa, dan tenaga kerja terlatih (skilled labour) serta aliran investasi yang lebih bebas. Dengan demikian persaingan universitas sebagai Lembaga pencetak tenaga kerja terdidik akan semakin terbuka. Upaya meningkatkan kualitas output pendidikan tinggi yang berkualitas membutuhkan pendidik yang berkualiats pula. Berkaitan dengan hal tersebut maka pendekatan karakter 4C (Communication, Collaboration, Critical Thinking and Problem Solving, Creativity and Innovation) diharapkan mampu menjadi solusi fenomena tersebut.

Komunikasi yang baik tidak selalu menjamin keberhasilan kinerja organisasi, ada banyak faktor yang dapat mengkondisikan perilaku masyarakat dalam berkomunikasi(Purwanto, Eijk, and Janssen n.d.). Dalam lingkungan yang tidak pasti, individu menghilangkan atau mengurangi validitas yang mereka berikan pada saluran komunikasi saat membuat keputusan (Bitektine and Haack 2015). Hal ini membuat mereka mempertanyakan kredibilitas organisasi, bahkan jika proses komunikasinya sesuai. Kondisi komunikasi organisasi memiliki dampak yang diinginkan adalah adanya hubungan kepercayaan dengan pemangku kepentingan (Piber, Demartini, and Biondi 2019).

Penelitian ini membahas peningkatan kinerja melalui pendekatan Dosen yang memiliki kemampuan berkomuniaksi, berkolaborasi, memiliki pemikiran kritis dan mampu menyelesaikan permasalahan serta dosen yang kreatif dan inovatif. Penelitian ini bertujuan untuk menyusun model kinerja dengan didukung karakter 4C (Communication, Collaboration, Critical Thinking and Problem Solving, Creativity).

\section{STUDI PUSTAKA}

1. Performance

Kinerja dosen dalam suatu institusi pendidikan dalam menghadapi era disruptive merupakan factor menarik untuk diteliti. Kinerja Dosen digambarkan sebagai sebuah perilaku nyata yang ditampilkan seorang dosen sebagai prestasi kerja yang dihasilkan sesuai perannya sebagai tenaga fungsional akademik (Bertram, Culver, and Gilbert 2017). Kinerja dosen didefinisikan sebagai tingkat keberhasilan selama periode tertentu dalam memenuhi standar hasil kerja, target yang telah ditentukan terlebih dahulu dan disepakati bersama sebagai seorang Dosen (Samian and Noor 2012). Kinerja dosen adalah kemampuan untuk melaksanakan pekerjaan atau tugas yang dimiliki dosen dalam menyelesaikan pekerjaannya (Sok-Foon et al. 2012). Kinerja dosen merupakan kualitas hasil kerja yang dilakukan oleh dosen dalam pengajaran atau proses belajar mengajar yang meliputi aspek-aspek kualitas hasil kerja, kemampuan, prakarsa/inisiatif, komunikasi, dan ketepatan waktu(Anggraeni 2014). 


\section{Fourfold C Aproach}

Pendidikan menjadi pondasi dasar dalam menghadapi persaingan yang semakin ketat. Di era revolusi industri ini, perkembangan teknologi dan informasi membutuhkan kecerdasan yang tinggi, berpikir kritis, kreatif, logis sehingga peserta didik dapat menerapkannya dalam kehidupan sehari - hari untuk memecahkan suatu masalah. Sehingga Dosen sebagai tenaga pendidik membutuhkan keterampilan - keterampilan dasar yaitu (1) berpikir kritis dan pemecahan masalah, (2) komunikasi, (3) kolaborasi, dan (4) kreativitas dan inovasi (4C)(Marlina and Jayanti 2019).

Critical Thinking and Problem Solving (berpikir kritis dan pemecahan masalah). Critical Thinking and Problem Solving merupakan suatu kemampuan untuk memahami sebuah masalah yang kompleks, yang memunculkan perspektif karena mampu mengoneksikan satu informasi dengan informasi lainnya, dan menemukan solusi yang tepat untuk suatu permasalahan (Rodzalan et al. 2019). Pemikiran kritis dan keterampilan pemecahan masalah penting dalam meningkatkan kelayakan kerja lulusan untuk memastikan bahwa mereka mampu dalam menghadapi kemajuan dalam konteks kerja (Holmes 2013). Dengan demikian, pentingnya keterampilan Critical Thinking and Problem Solving pada Dosen telah mendorong perguruan tinggi untuk memainkan peran yang lebih signifikan dalam menghasilkan lulusan berkualitas tinggi yang tidak hanya dengan keterampilan teknis tetapi juga dengan keterampilan lunak yang dibutuhkan. Salah satu upaya yang dilakukan oleh perguruan tinggi dalam meningkatkan kemampuan berpikir kritis dan pemecahan masalah. Upaya ini didasarkan pada gagasan bahwa universitas dapat dan harus menghasilkan lulusan holistik yang siap untuk pekerjaan masa depan (Jackson 2014). Kemampuan Dosen untuk Critical Thinking and Problem Solving diharapkan mampu ditularkan pada mahasiswanya untuk meningkatkan pemikiran kritis dan keterampilan memecahkan masalah (Jackson 2014). Sebuah studi oleh Dvergsten dan Haugen (Rodzalan et al. 2019) menggunakan studi pra dan pasca menemukan bahwa pembelajaran berdasarkan pengalaman adalah cara yang efektif untuk meningkatkan keterampilan berpikir kritis siswa.

\section{H1 : Semakin baik berpikir kritis dan pemecahan masalah maka akan semakin tinggi kinerjanya.}

Communication (komunikasi) adalah interaksi sosial antar seseorang yang saling menyampaikan gagasannya (Sok-Foon et al. 2012). Communication merupakan kegiatan mentransfer informasi baik secara tertulis maupun lisan (Han and goleman, daniel; boyatzis, Richard; Mckee 2019). Komunikasi adalah salah satu elemen paling mendasar dari fungsi manusia, sehingga memiliki dampak langsung pada kualitas hubungan interpersonal (Zahner and Lehrfeld 2019). Penggunaan keterampilan komunikasi yang efektif adalah kompetensi interpersonal yang penting (Nørgaard et al. 2012). Communication skill adalah kemampuan untuk berkomunikasi dengan baik (Moore et al. 2018). Communication skill ditunjukkan dengan kemampuan untuk menyampaikan informasi atau pesan terhadap orang lain (Nørgaard et al. 2012).

\section{H2 :Communication skills dikembangkan sebagai pendukung peningkatan kinerja}

Collaboration (kolaborasi) adalah bentuk kerjasama untuk mencapai tujuan yang diinginkan secara kelompok (Ritala and Hurmelinna-Laukkanen 2013). Collaboration merupakan kemampuan untuk bersinergi, bekerja secara produktif dengan pihak lain, 
beradaptasi dalam berbagai tanggung jawab dan peran, menghormati perspektif yang berbeda, dan menempatkan empati pada tempatnya (de Groot 2020). Collaboration adalah bentuk kerjasama, interaksi, kompromi beberapa elemen yang terkait baik individu, lembaga dan atau pihak-pihak yang terlibat secara langsung dan tidak langsung yang menerima akibat dan manfaat(Maican et al. 2019). Collaboration adalah bentuk proses partisipasi beberapa orang atau kelompok untuk mencapai hasil tertentu (Ivanova et al. 2020). Collaboration adalah bentuk kerjasama untuk mencapai hasil yang diinginkan dan menumbuhkan kepercayaan diantara pihak yang terkait (Banaeianjahromi and Smolander 2019). Sehingga dapat disimpulkan bahwa collaboration adalah segala bentuk kerjasama diantara berbagai pihak dalam rangka meraih hasil yang telah disepakati bersama. Dalam menciptakan kinerja tim yang hebat, kolaborasi memiliki peran yang sangat penting. Kolaborasi merupakan trigger dari kepercayaan dan ahirnya meningkatkan kinerja(Banaeianjahromi and Smolander 2019). Sehingga hipothesis yang diajukan adalah :

\section{H3 : Semakin baik kolaborasi maka akan semakin tinggi kinerjanya}

Creativity and Innovation (kreatifitas dan inovasi). Creativity and Innovation merupakan suatu kemampuan untuk menyampaikan dan mengembangkan gagasan-gagasan baru kepada pihak lain, bersikap responsif dan menerima dengan terbuka terhadap perspektif yang baru dan berbeda(Rodzalan et al. 2019). Kreativitas telah menjadi semboyan di zaman kontemporer: menjadi kreatif adalah satu-satunya cara untuk melakukan apa pun dan moda bertahan yang paling jitu. Individu yang akan mampu bertahan adalah mereka yang memiliki modal berbasis intelektual (Widodo 2018b); memiliki sumber daya intelektual yang strategis(Widodo 2018a); memiliki kapasitas untuk membentuk jejaring sosial (Kao and Wu 2016); pertukaran pengetahuan (Singh 2018); memiliki kreativitas (Carvalho 2020) dan daya inovasi yang tinggi (Wardhani and Widodo 2020).

\section{H4 : Semakin baik kreatifitas dan inovasi maka akan semakin tinggi kinerjanya}

\section{METODOLOGI PENELITIAN}

Populasi penelitian ini adalah dosen di universitas Boyolali yang berjumlah 115 Orang. sample ditentukan dengan tehnik sensus dimana keseluruhan populasi merupakan sample. Responden penelitian ini adalah Dosen Universitas Boyolali sebanyak 115 dosen. Data didapatkan melalui kuesioner skala likert $1-5$ dan dianalisis dengan menggunakan SPSS.

\section{HASIL PENELITIAN}

Uji validitas menguji masing-masing variabel yang digunakan dalam penelitian ini. Keseluruhan variabel penelitian memuat 20 pernyataan yang harus dijawab oleh responden. Adapun kriteria yang digunakan dalam menentukan valid tidaknya pernyataan yang digunakan dalam penelitian ini adalah sebagai berikut: tingkat kepercayaan $=95 \%$ ( $\square=5$ persen), derajat kebebasan (df) $=n-2$, diperoleh $r$ tabel $=0,183$ (uji dua sisi). Jika $\mathrm{r}$ hitung (nilai pearson correlation) lebih besar dari $r$ tabel dan nilai $r$ positif, maka butir pernyataan dikatakan valid (Ghozali, 2011). 
Tabel 1. Hasil Uji Validitas

\begin{tabular}{cccccc} 
Variabel & Indikator & Kode Item & r hitung & r tabel & Keterangan \\
\hline \multirow{2}{*}{ Critical } & 1 & $\mathrm{X} 1.1$ & 0,794 & 0,183 & Valid \\
Thinking and & 2 & $\mathrm{X} 1.2$ & 0,815 & 0,183 & Valid \\
Problem & 3 & $\mathrm{X} 1.3$ & 0,574 & 0,183 & Valid \\
Solving & 4 & $\mathrm{X} 1.4$ & 0,703 & 0,183 & Valid \\
& 5 & $\mathrm{X} 1.5$ & 0,688 & 0,183 & Valid \\
Communication & 1 & $\mathrm{X} 2.1$ & 0,869 & 0,183 & Valid \\
skills & 2 & $\mathrm{X} 2.2$ & 0,835 & 0,183 & Valid \\
& 3 & $\mathrm{X} 2.3$ & 0,738 & 0,183 & Valid \\
& 4 & $\mathrm{X} 2.4$ & 0,554 & 0,183 & Valid \\
Collaboration & 1 & $\mathrm{X} 3.1$ & 0,786 & 0,183 & Valid \\
& 2 & $\mathrm{X} 3.2$ & 0,738 & 0,183 & Valid \\
& 3 & $\mathrm{X} 3.3$ & 0,648 & 0,183 & Valid \\
Creativity & 4 & $\mathrm{X} 3.4$ & 0,791 & 0,183 & Valid \\
& 1 & $\mathrm{Y} 1.1$ & 0,804 & 0,183 & Valid \\
& 2 & $\mathrm{Y} 1.2$ & 0,765 & 0,183 & Valid \\
& 3 & $\mathrm{Y} 1.3$ & 0,802 & 0,183 & Valid \\
Performance & 1 & $\mathrm{Y} 2.1$ & 0,829 & 0,183 & Valid \\
& 2 & $\mathrm{Y} 2.2$ & 0,855 & 0,183 & Valid \\
& 3 & $\mathrm{Y} 2.3$ & 0,668 & 0,183 & Valid \\
& 4 & $\mathrm{Y} 2.4$ & 0,544 & 0,183 & Valid \\
\hline
\end{tabular}

Sumber: Data primer yang diolah, 2020

Berdasarkan Tabel 1 diketahui bahwa nilai $r$ hitung dari semua indikator lebih besar dari nilai $r$ tabel. Oleh karena itu dapat disimpulkan bahwa semua indikator dalam penelitian ini adalah valid.

Reliabilitas adalah alat untuk mengukur suatu kuesioner yang merupakan alat pengukuran konstruk atau variabel. Kuesioner dikatakan reliabel atau handal jika jawaban seseorang, terhadap pernyataan tersebut konsisten atau stabil dari waktu ke waktu (Ghozali, 2011). Uji reliabilitas adalah tingkat kestabilan suatu alat pengukur dalam mengukur suatu gejala/kejadian. Semakin tinggi reliabilitas suatu alat pengukur, semakin stabil pula alat pengukur tersebut. Suatu konstruk dikatakan reliabel jika memberikan nilai Cronbach Alpha > 0,60 (Ghozali, 2005).

Tabel 2 Hasil Uji Reliabilitas

\begin{tabular}{lcc}
\multicolumn{1}{c}{ Variabel } & Cronbach Alpha & Status \\
Critical Thinking and Problem & 0,761 & Reliabel \\
Solving & & \\
Communication skills & 0,715 & Reliabel \\
Collaboration & 0,721 & Reliabel \\
Creativity & 0,698 & Reliabel \\
Performance & 0,766 & Reliabel \\
\hline Drfipe
\end{tabular}

Sumber: Data primer yang diolah, 2020

Multikolinieritas dalam model regresi pada penelitian ditentukan berdasarkan nilai VIF (variance inflation factor) dan tolerance. Adapun nilai VIF dapat dilihat pada Tabel 3 di bawah ini: 
Tabel 3 Nilai Tolerance dan VIF

\begin{tabular}{|ll|r|c|}
\hline Model & \multicolumn{2}{|c|}{ Collinearity Statistics } \\
\cline { 3 - 4 } \multicolumn{1}{|l|}{ (Constant) } & \multicolumn{1}{|c|}{ Tolerance } & \multicolumn{1}{c|}{ VIF } \\
\hline Critical Thinking and Problem Solving &, 561 & 1,783 \\
Communication skills &, 781 & 1,280 \\
Collaboration &, 472 & 2,117 \\
Creativity &, 751 & 1,140 \\
\hline
\end{tabular}

Sumber: Data primer yang diolah, 2020

Dari Tabel 3 terlihat bahwa tidak ada variabel yang memiliki nilai VIF lebih besar dari 10 dan nilai tolerance yang lebih kecil dari 0,1 yang berarti bahwa tidak terdapat korelasi antar variabel bebas. Sehingga dapat disimpulkan bahwa tidak terdapat multikolinieritas antar variabel bebas dalam model regresi ini. Berikut hasil pengujian heterokedastisitas dengan menggunakan uji Glejser dengan meregresikan variabel bebas dengan nilai absolute dari unstandardized residuals. Hasil dari uji Glejser dapat dilihat sebagai berikut:

Tabel 4 Hasil Uji Glejser Coefficients $^{\mathrm{a}}$

\begin{tabular}{|c|c|c|c|c|c|c|}
\hline \multirow{2}{*}{\multicolumn{2}{|c|}{ Model }} & \multicolumn{2}{|c|}{$\begin{array}{l}\text { Unstandardized } \\
\text { Coefficients }\end{array}$} & \multirow{2}{*}{\begin{tabular}{|c|}
$\begin{array}{c}\text { Standardized } \\
\text { Coefficients }\end{array}$ \\
Beta \\
\end{tabular}} & \multirow[b]{2}{*}{$\mathrm{t}$} & \multirow[b]{2}{*}{ Sig. } \\
\hline & & B & $\begin{array}{l}\text { Std. } \\
\text { Error }\end{array}$ & & & \\
\hline \multirow[t]{5}{*}{1} & (Constant) & 2,314 & ,782 & & 2,960 & ,004 \\
\hline & $\begin{array}{l}\text { Critical Thinking and Problem } \\
\text { Solving }\end{array}$ &,- 041 & 044 &,- 115 &,- 932 & ,354 \\
\hline & Communication skills & ,047 & ,040 &, 122 & 1,164 & ,247 \\
\hline & Collaboration &,- 064 & 058 &,- 148 & $-1,098$ & ,275 \\
\hline & Creativity &,- 044 &, 082 &,- 228 & $-1,231$ & ,283 \\
\hline
\end{tabular}

a. Dependent Variable: Performance

Sumber: Data primer yang diolah, 2020

Berdasarkan hasil uji Glejser, nilai signifikansi dari semua variabel bebas $>0,05$ sehingga dapat dikatakan model regresi ini bebas dari heteroskedastisitas.

Tabel 5 Uji Kolmogrov-Smirnov

One-Sample Kolmogorov-Smirnov Test

\begin{tabular}{|ll|r|}
\hline & & Unstandardized Residual \\
\hline Normal Parameters & & 115 \\
& & Mean \\
Nost Extreme & Std. Deviation &, 0000000 \\
Mosterences & Absolute & 1,58857570 \\
Differen & Positive &, 092 \\
& Negative &, 085 \\
Kolmogorov-Smirnov Z &,- 092 \\
Asymp. Sig. (2-tailed) &, 986 \\
\hline
\end{tabular}

a. Test distribution is Normal.

b. Calculated from data.

Sumber: Data primer yang diolah, 2020 
Dari tabel 4.13 di atas, terlihat bahwa Asymp Sig $(0,286)>0,05$, sehingga dapat dikatakan bahwa data terdistribusi normal. Analisis regresi linier berganda yang telah dilakukan diperoleh koefisien regresi, nilai $\mathrm{t}$ hitung dan tingkat signifikansi sebagaimana ditampilkan pada Tabel 6 sebagai berikut:

Tabel 6 Hasil Uji Rgresi Linier Berganda Coefficients $^{\mathrm{a}}$

\begin{tabular}{|c|c|c|c|c|c|c|}
\hline \multirow{2}{*}{\multicolumn{2}{|c|}{ Model }} & \multicolumn{2}{|c|}{$\begin{array}{c}\text { Unstandardized } \\
\text { Coefficients }\end{array}$} & \multirow{2}{*}{$\begin{array}{c}\begin{array}{c}\text { Standardized } \\
\text { Coefficients }\end{array} \\
\text { Beta }\end{array}$} & \multirow[b]{2}{*}{$t$} & \multirow[b]{2}{*}{ Sig. } \\
\hline & & B & Std. Error & & & \\
\hline \multirow[t]{5}{*}{1} & (Constant) & 2,819 & 1,199 & & 2,352 &, 020 \\
\hline & $\begin{array}{l}\text { Critical } \\
\text { Thinking and } \\
\text { Problem } \\
\text { Solving }\end{array}$ & ,269 & ,068 & ,387 & 3,952 & ,000 \\
\hline & $\begin{array}{l}\text { Communication } \\
\text { skills }\end{array}$ &, 073 &, 062 & ,098 & 1,179 & ,241 \\
\hline & Collaboration & ,286 & ,089 & ,343 & 3,215 & ,002 \\
\hline & Creativity & 244 & ,0865 & ,333 & 3,521 &, 004 \\
\hline
\end{tabular}

a. Dependent Variable: Performance

Sumber: Data primer yang diolah, 2020

Dari hasil tersebut, persamaan regresi yang diperoleh adalah:

$\mathrm{Y}=0,387 \mathrm{X}_{1}+0,098 \mathrm{X}_{2}+0,343 \mathrm{X}_{3}+0,333 \mathrm{X} 4+\mathrm{e}$

Persamaan regresi berganda tersebut dijelaskan sebagai berikut:

1. Variabel Critical Thinking and Problem Solving (X1) mempunyai pengaruh positif terhadap Performance(Y) dengan nilai 0,387; artinya semakin baik Critical Thinking and Problem Solving maka Performance semakin meningkat.

2. Variabel Communication skills (X2) mempunyai pengaruh positif terhadap Performance $(\mathrm{Y})$ dengan nilai 0,098; artinya semakin baik Communication skills maka Performance semakin meningkat.

3. Variabel Collaboration (X3) mempunyai pengaruh positif terhadap Performance (Y) dengan nilai 0,343; artinya semakin baik Collaboration maka Performance semakin meningkat.

4. Variabel Creativity (X4) mempunyai pengaruh positif terhadap Performance (Y) dengan nilai 0,333; artinya semakin baik Collaboration maka Performance semakin meningkat.

Koefisien Determinasi $\left(\mathrm{R}^{2}\right)$ pada intinya mengukur seberapa jauh kemampuan model dalam menerangkan variasi variabel dependen. Nilai koefisien determinasi adalah antara nol dan satu (Ghozali, 2011). Nilai koefisien determinasi dapat dilihat Tabel 7 di bawah ini:

Tabel 7 Hasil Uji Koefisien Determinasi $\left(\mathbf{R}^{2}\right)$ Model Summary ${ }^{\mathrm{b}}$

\begin{tabular}{|l|c|c|r|r|}
\hline Model & $\mathrm{R}$ & $\begin{array}{c}\mathrm{R} \\
\text { Square }\end{array}$ & $\begin{array}{c}\text { Adjusted } \\
\text { R Square }\end{array}$ & $\begin{array}{c}\text { Std. Error of } \\
\text { the Estimate }\end{array}$ \\
\hline dimension 1 &, $634^{\mathrm{a}}$ &, 402 &, 386 & 1,610 \\
\hline
\end{tabular}


a. Predictors: (Constant), Critical Thinking and Problem Solving and Problem Solving, Communication skills, Creativity

b. Dependent Variable: Performance

Dari Tabel 7 terlihat tampilan output SPSS model summary besarnya adjusted R square adalah 0,386. Hal ini berarti hanya 38,6\% variasi performance (Y) dapat dijelaskan oleh variabel-variabel independen di atas. Sedang sisanya $(100 \%-38,6 \%=61,4 \%)$ dijelaskan oleh sebab-sebab lain di luar model. Ketepatan fungsi regresi sampel dalam menaksir nilai aktual dapat dinilai dengan goodness of fit test-nya. Secara statistik setidaknya ini dapat diukur dari nilai koefisien determinasi, nilai statistik F dan nilai statistik t (Ghozali, 2011). Uji F digunakan untuk menguji ada tidaknya pengaruh variabel-variabel independen terhadap variabel dependen secara simultan (bersama-sama).

Tabel 8 Hasil Uji F

ANOVA ${ }^{b}$

\begin{tabular}{|ll|r|r|r|r|r|}
\hline \multicolumn{1}{|l|}{ Model } & \multicolumn{1}{|c|}{$\begin{array}{c}\text { Sum of } \\
\text { Squares }\end{array}$} & df & Mean Square & F & Sig. \\
\hline 1 & Regression & 193,408 & 3 & 64,469 & 24,875 &, $000^{\mathrm{a}}$ \\
& Residual & 287,687 & 111 & 2,592 & & \\
& Total & 481,096 & 114 & & & \\
\hline
\end{tabular}

a. Predictors: (Constant), Problem Solving, Communication skills, Creativity

b. Dependent Variable: performance

Berdasarkan uji Anova atau F test, maka dapat diperoleh F hitung sebesar 24,875 dengan tingkat signifikansi 0,000 . Oleh karena probabilitas jauh lebih kecil daripada $0,05(0,000$ $<0,05)$ dan F hitung lebih besar daripada F tabel $(24,875>2,69)$ maka dapat dinyatakan bahwa variabel independen yang meliputi Critical Thinking and Problem Solving and Problem Solving, Communication skills, dan Creativity secara simultan atau bersamasama mempengaruhi variabel Invesment Decision (Y) secara signifikan.

Tabel 9 Hasil Uji T

Coefficients $^{\mathrm{a}}$

\begin{tabular}{|c|c|c|c|c|c|c|}
\hline \multirow{2}{*}{\multicolumn{2}{|c|}{ Model }} & \multicolumn{2}{|c|}{$\begin{array}{l}\text { Unstandardized } \\
\text { Coefficients }\end{array}$} & \multirow{2}{*}{$\begin{array}{c}\text { Standardized } \\
\text { Coefficients } \\
\text { Beta } \\
\end{array}$} & \multirow[t]{2}{*}{$\mathrm{t}$} & \multirow[t]{2}{*}{ Sig. } \\
\hline & & $\mathrm{B}$ & $\begin{array}{l}\text { Std. } \\
\text { Error }\end{array}$ & & & \\
\hline \multirow[t]{5}{*}{1} & (Constant) & 2,819 & 1,199 & & 2,352 &, 020 \\
\hline & $\begin{array}{l}\text { Critical Thinking and Problem } \\
\text { Solving }\end{array}$ & ,269 & ,068 & ,387 & 3,952 &, 000 \\
\hline & Communication skills &, 073 & ,062 & ,098 & 1,179 & ,241 \\
\hline & Collaboration & ,286 & ,089 & ,343 & 3,215 & ,002 \\
\hline & Creativity & ,278 &, 077 & ,456 & 3,929 &, 000 \\
\hline
\end{tabular}

a. Dependent Variable: Investment Decision

Sumber: Data primer yang diolah, 2020 
Dari Tabel 9 diatas terlihat bahwa:

Dari hasil perhitungan SPSS, dapat diketahui signifikansi variabel Critical Thinking and Problem Solving sebesar 0,000. Oleh karena probabilitas di bawah 0,05 maka koefisien regresi dari Critical Thinking and Problem Solving adalah signifikan, sedangkan $t$ hitung $(3,952)$ lebih besar daripada t tabel $(1,98)$ maka Ho ditolak dan Ha diterima. Hal ini berarti bahwa Critical Thinking and Problem Solving berpengaruh terhadap performance. Berarti hipotesis yang berbunyi: Critical Thinking and Problem Solving berpengaruh terhadap performance adalah diterima.

Dari hasil perhitungan SPSS, dapat diketahui signifikansi variabel Communication skills sebesar 0,241. Oleh karena probabilitas di atas 0,05 maka koefisien regresi dari Communication skills adalah tidak signifikan, sedangkan t hitung $(1,179)$ lebih kecil daripada t tabel $(1,98)$ maka Ho diterima dan Ha ditolak. Hal ini berarti bahwa Communication skills tidak berpengaruh terhadap performance. Berarti hipotesis yang berbunyi: Communication skills berpengaruh terhadap performance ditolak.

Dari hasil perhitungan SPSS, dapat diketahui signifikansi variabel Collaboration sebesar 0,002. Oleh karena probabilitas di bawah 0,05 maka koefisien regresi dari Collaboration adalah signifikan, sedangkan thitung $(3,215)$ lebih besar daripada t tabel $(1,98)$ maka Ho ditolak dan Ha diterima. Hal ini berarti bahwa Collaboration berpengaruh terhadap performance. Berarti hipotesis yang berbunyi: Collaboration berpengaruh terhadap performance adalah diterima.

Dari hasil perhitungan SPSS, dapat diketahui signifikansi variabel Creativity sebesar 0,000. Oleh karena probabilitas di bawah 0,05 maka koefisien regresi dari Creativity adalah signifikan, sedangkan t hitung $(3,929)$ lebih besar daripada t tabel $(1,98)$ maka Ho ditolak dan Ha diterima. Hal ini berarti bahwa Creativity berpengaruh terhadap performance. Berarti hipotesis yang berbunyi: Creativity berpengaruh terhadap performance adalah diterima.

\section{Implications Managerial}

Penelitian ini Memberikan wawasan yang lebih baik tentang faktor-faktor yang berpotensi mempengaruhi kinerja Dosen di Perguruan tinggi di Universitas Boyolali melalui Critical Thinking and Problem Solving, Communication skills, collaboration dan Creativity. Pengujian dan pembuktian proposisi ini harus menyediakan model peningkatan kinerja yang lebih lengkap. Artikel ini memberikan pemahaman yang lebih dalam tentang masalah kontekstual penting yang berdampak pada upaya implementasi strategi pendekatan Fourfold $C$ dalam meningkatkan kinerja DOsen sehingga dapat berguna sebagai bahan acuan rencana pengembangan karakter dan kompetensi SDM dan menjadi salah satu referensi bagi peneliti-peneliti lain yang akan mengambil tema sejenis.

\section{4. $\quad$ Limitations and Future Research}

Hasil penelitian ini menunjukkan nilai B variable communication Skill yang rendah sehingga tidak mampu meningkatkan kinerja SDM. Penelitian ini membahas tentang peningkatan kinerja melalui pendekatan 4C namun belum memperhatikan besar pengaruh bersama sama terhadap kinerja. Penelitian ini memberikan black box yang cukup luas untuk penelitian mendatang, untuk menganalisis pengaruh komunikasi terhadap kinerja pada obyek penelitian lain yang lebih luas dan heterogen. 


\section{KESIMPULAN}

Penelitian ini mengusulkan konsep peningkatan kinerja Dosen melalui melalui Critical Thinking and Problem Solving, Communication skills, dan Creativity. Hasil penelitian ini menunjukkan bahwa kinerja Dosen dapat ditingkatkan melalui melalui Critical Thinking and Problem Solving; collaboration dan Creativity. Communication skill tidak mampu menjadi predictor kinerja Dosen karena budaya yang ada dalam masyarakat jawa, yang kurang memiliki efektifitas dalam berkomunikasi dan berpotensi menimbulkan konflik. Ketika komunikasi yang dilakukan melewati batas maka yang terjadi adalah waktu yang terbuang, berpotensi konflik, bocornya rahasia perusahaan, dan lains ebagainya. Ketika komunikasi tidak sesuai dengan peruntukannya maka yang terjadi adalah penurunan kinerja.

\section{DAFTAR PUSTAKA}

Anggraeni, Rinny Dewi. 2014. "Increasing Lecturer Competence as the Quality Assurance of Lecturer Performance.” Management Studies 2(5):309-29.

Banaeianjahromi, Negin, and Kari Smolander. 2019. "Lack of Communication and Collaboration in Enterprise Architecture Development." Information Systems Frontiers 21(4):877-908.

Bertram, Rachael, Diane M. Culver, and Wade Gilbert. 2017. "A University Sport Coach Community of Practice: Using a Value Creation Framework to Explore Learning and Social Interactions. ” 0(0):1-16.

Bitektine, Alex, and Patrick Haack. 2015. "The Macro and the Micro of Legitimacy: Towards a Multi-Level Theory of the Legitimacy Process." Zurich Open Repository and Archive 40:49-75.

Carvalho, R. 2020. "The Need for Creative Actions in Tourism in the Post-COVID 19 Pandemic World." Turismo Mundial, Crise Sanitária Futuro: Visões Globais Partilhadas (June):177-90.

de Groot, Steven. 2020. "Collaboration of Creative Professionals with Companies (CoCreaCo): Antecedent Conditions for Collaboration in Crossovers. ” Journal of Work-Applied Management 12(2):159-74.

Han, Eunice S., and Annie goleman, daniel; boyatzis, Richard; Mckee. 2019. "THE IMPORTANCE OF SOFT SKILLS IN THE WORKPLACE AS PERCEIVED BY COMMUNITY COLLEGE INSTRUCTORS AND INDUSTRIES." Journal of Chemical Information and Modeling 53(9):1689-99.

Holmes, Leonard. 2013. "Competing Perspectives on Graduate Employability: Possession , Position or Process ?” 38(4):538-54.

Ivanova, I. A., V. N. Pulyaeva, L. V. Vlasenko, A. A. Gibadullin, and B. G. Safarov. 2020. "Collaboration of Different Generations in the Digital Environment of the Economy.” IOP Conference Series: Earth and Environmental Science 421(3). 
Jackson, Denise. 2014. "Employability Skill Development in Work-Integrated Learning : Barriers and Best Practice.” (January):1-18.

Kao, Shu Chen, and Chien Hsing Wu. 2016. "The Role of Creation Mode and Social Networking Mode in Knowledge Creation Performance: Mediation Effect of Creation Process. " Information and Management 53(6):803-16.

Maican, Catalin Ioan, Ana Maria Cazan, Radu Constantin Lixandroiu, and Lavinia Dovleac. 2019. "A Study on Academic Staff Personality and Technology Acceptance: The Case of Communication and Collaboration Applications." Computers and Education 128(March 2018):113-31.

Marlina, Winda, and Dhitsaha Jayanti. 2019. "4C DALAM PEMBELAJARAN MATEMATIKA UNTUK MENGHADAPI ERA REVOLUSI INDUSTRI 4.0.” Prosiding Sendika 5(1):2-6.

Moore, S. Rivera, Bravo-soto Ga, C. Olivares, Lawrie Ta, Moore Pm, S. Rivera, Bravosoto Ga, C. Olivares, and Lawrie Ta. 2018. "Communication Skills Training for Healthcare Professionals Working with People Who Have Cancer (Review)." Cochrane Database of Systematic Reviews Communication (7).

Nørgaard, Birgitte, Jette Ammentorp, Poul Erik Kofoed, and Kirsten Ohm Kyvik. 2012. "Training Improves Inter-Collegial Communication." 173-77.

Piber, Martin, Paola Demartini, and Lucia Biondi. 2019. "The Management of Participatory Cultural Initiatives: Learning from the Discourse on Intellectual Capital. " Journal of Management and Governance 23(2):435-58.

Purwanto, Arie, Anneke Zuiderwijk-van Eijk, and Marijn Janssen. n.d. "Group Development Stages in Open Government Data Engagement Initiatives : A Comparative Case Studies Analysis."

Ritala, Paavo, and Pia Hurmelinna-Laukkanen. 2013. "Incremental and Radical Innovation in Coopetition-the Role of Absorptive Capacity and Appropriability. ” Journal of Product Innovation Management 30(1):154-69.

Rodzalan, Shazaitul Azreen, Noor Nazihah Mohd Noor, Lily Suriani Mohd Arif, and Maisarah Mohamed Saat. 2019. "Factors Influencing the Improvement of Students 'Critical Thinking and Problem-Solving Skill An Industrial Training Intervention." 134-45.

Samian, Yahya, and Norah Md Noor. 2012. "Student's Perception on Good Lecturer Based on Lecturer Performance Assessment." Procedia - Social and Behavioral Sciences 56(Ictlhe):783-90.

Singh, Pooja K. 2018. "Knowledge Strategy, Sharing Behavior and Performance: Reviewing a Knowledge-Oriented Approach." Management Research Review 41(3):395-411. 
Sok-Foon, Yeoh, Jessica Ho Sze-Yin, Benjamin Chan Yin-Fah, and Benjamin Chan Yin. 2012. "Student Evaluation of Lecturer Performance Among Private University Students.” Canadian Social Science 8(84):238-43.

Wardhani, Windi N. R., and Widodo Widodo. 2020. "Destination Innovativeness Towards Tourism Competitive Advantage.” 149(Apmrc 2019):39-45.

Widodo. 2018a. " The Model of Human Capital and Knowledge Sharing towards Sustainable Competitive Advantages 'The Model of Human Capital and Knowledge Sharing towards Sustainable Competitive Advantages."

Widodo. 2018b. "Grand Theory Model of Strategy Quality: Strategic Asset Approach at Industry." Academy of Strategic Management Journal 17(2):1-10.

Zahner, Doris, and Jon Lehrfeld. 2019. 'Employers' and Advisors' Assessments of the Importance of Critical Thinking and Written Communication Skills PostCollege. "Journal of Chemical Information and Modeling 53(9):1689-99 